\title{
An overview of systematic reviews of pharmacological and non-pharmacological interventions for the treatment of behavioral and psychological symptoms of dementia
}

\author{
Suzanne M. Dyer, ${ }^{1,2}$ Stephanie L. Harrison, ${ }^{1,2}$ Kate Laver, $^{1,2}$ Craig Whitehead ${ }^{1,2}$ \\ and Maria Crotty ${ }^{1,2}$ \\ ${ }^{1}$ Department of Rehabilitation, Aged and Extended Care, Faculty of Medicine, Nursing and Health Sciences, School of Health Sciences, Flinders University \\ Level 1, C Block, Repatriation General Hospital, Daw Park, SA, Australia \\ ${ }^{2}$ NHMRC Cognitive Decline Partnership Centre, The University of Sydney, Sydney NSW, Australia
}

Background: This systematic overview reports findings from systematic reviews of randomized controlled trials of pharmacological and non-pharmacological interventions for behavioural and psychological symptoms of dementia (BPSD).

Methods: The Cochrane Database of Systematic Reviews, DARE, Medline, EMBASE, and PsycINFO were searched to September 2015.

Results: Fifteen systematic reviews of eighteen different interventions were included. A significant improvement in BPSD was seen with: functional analysis-based interventions (GRADE quality of evidence moderate; standardized mean difference (SMD) $-0.10,95 \% \mathrm{CI}-0.20$ to 0.00 ), music therapy (low; SMD $-0.49,95 \% \mathrm{CI}-0.82$ to -0.17 ), analgesics (low; SMD $-0.24,95 \% \mathrm{CI}-0.47$ to -0.01 ), donepezil (high; SMD $-0.1595 \%$ CI -0.29 to -0.01 ), galantamine (high; SMD $-0.15,95 \%$ CI -0.28 to -0.03 ), and antipsychotics (high; SMD $-0.13,95 \% \mathrm{CI}-0.21$ to -0.06 ). The estimate of effect size for most interventions was small.

Conclusions: Although some pharmacological interventions had a slightly larger effect size, current evidence suggests functional analysis-based interventions should be used as first line management of BPSD whenever possible due to the lack of associated adverse events. Music therapy may also be beneficial, but further research is required as the quality of evidence to support its use is low. Cholinesterase inhibitors donepezil and galantamine should be trialled for the management of BPSD where non-pharmacological treatments have failed. Low-quality evidence suggests that assessment of pain should be conducted and a stepped analgesic approach trialled when appropriate. Antipsychotics have proven effectiveness but should be avoided where possible due to the high risk of serious adverse events and availability of safer alternatives.

Key words: dementia, behavioral symptoms, systematic review, antipsychotics, cholinesterase inhibitors, complementary therapies

\section{Introduction}

Dementia is an age-related condition and as the proportion of older people in the population increases, the prevalence of dementia is also expected to increase (Alzheimer's Disease International, 2015). Dementia is primarily characterized

Correspondence should be addressed to: Suzanne M. Dyer, Department of Rehabilitation, Aged and Extended Care, Faculty of Medicine, Nursing and Health Sciences, School of Health Sciences, Flinders University, Level 1, C Block, Repatriation General Hospital, Daws Road, Daw Park, SA 5041, Australia. Phone: +61 882751103 (x51680); Fax: +61 88275 1175. Email: sue.dyer@flinders.edu.au; suzanne.dyer@sa.gov.au. Received 30 Jan 2017; revision requested 12 Jul 2017; revised version received 20 Sep 2017; accepted 25 Sep 2017. First published online 16 November 2017. by a gradual decrease in cognitive functioning. As people living with dementia experience this decline, their ability to communicate and to express their needs deteriorates and their unmet needs may be expressed as changed behaviors, or behavioral and psychological symptoms of dementia (BPSD). BPSD is a broad term for behaviors and neuropsychiatric symptoms which may be experienced by people living with dementia, including mood disorders, depression, agitation, psychosis, sleep disturbances, anxiety, apathy, dysphoria, aberrant motor activity, hallucinations, and delusions (Lyketsos et al., 2000). These symptoms are common among people with dementia and 
may affect nearly all people with dementia at some point (Savva et al., 2009). The prevalence and severity of different symptoms of BPSD is likely to vary depending on the person's level of cognitive functioning and stage of dementia (Cerejeira et al., 2012). BPSD has been associated with increased loss of functioning and has a large impact on health by reducing quality of life, increasing caregiver burden, and increasing the costs associated with dementia care (Moore et al., 2001). Furthermore, increasing severity of BPSD has also been reported to be one of the major reasons for a person with dementia to move to residential care (Steele et al., 1990). While Alzheimer's disease is the most common form of dementia, and is often associated with apathy and depression, other subtypes of dementia can be associated with different behavioral change profiles, which may be more prominent than other cognitive symptoms such as memory loss. In particular, personality, disinhibition and mood changes may be the first symptoms observed in frontotemporal dementia and mood fluctuations may be prominent in vascular dementia (Alzheimer's Disease International, 2009).

Many existing systematic reviews, including a number of reviews conducted by The Cochrane Collaboration, exist which summarize the evidence individually for the wide range of interventions available to manage BPSD. However, a succinct summary of the findings of these reviews across the different types of treatments, including both pharmacological and non-pharmacological options has not been conducted. An overview of reviews is considered suitable in order to summarize the evidence across the range of interventions (Higgins and Green, 2011).

Non-pharmacological interventions are recommended as first line treatment for BPSD (Guideline Adaptation Committee, 2016; National Institute for Health and Clinical Excellence-Social Care Institute for Excellence, 2007). However, the high rate of use of antipsychotics in people with dementia in residential care settings suggests that this may not be the case in practice (Chen et al., 2010). This review of systematic reviews aims to provide an overview of the effectiveness of the different pharmacological and non-pharmacological interventions available to treat BPSD, in order to compare their relative evidence base and likely magnitude of effect.

\section{Methods}

A protocol for this overview of systematic reviews was registered on the PROSPERO International Prospective Register of Systematic Reviews (regis- tration number CRD42016039477). The protocol provides full details of the methods used and the only change made to the protocol following registration was that studies were required to have an AMSTAR rating of five or greater (from a possible score of 11) for inclusion. The review was undertaken in accordance with the PRISMA statement (Moher et al., 2011).

\section{Inclusion and exclusion criteria}

\section{TyPES OF STUDies}

This overview included systematic reviews of randomized controlled trials (RCTs). Only Cochrane reviews and systematic reviews previously published in peer-reviewed journals were eligible for inclusion. Systematic reviews that were published in languages other than English or before the year 2000 were excluded. The methods used in this overview were consistent with methods from a previous published overview (Laver et al., 2016).

\section{Population}

Systematic reviews were included that examined adults with dementia (of any type including Alzheimer's disease) or adults with Alzheimer's disease, of any severity or in any setting. Reviews were excluded if they only examined outcomes for non-Alzheimer's disease dementias, for example, reviews that only examined adults with vascular dementia as it did not seem appropriate to compare studies conducted in populations with different types of dementia due to the varied BPSD profiles. Although BPSD is prominent in other types of dementia, previous work had indicated that most existing reviews were for Alzheimer's dementia or mixed dementia subtype populations (Guideline Adaptation Committee, 2016).

\section{INTERVENTION AND COMPARISON}

Reviews that examined RCTs of either pharmacological or non-pharmacological interventions for the treatment of BPSD, in comparison to placebo or usual care, were included. Following review of recently completed Australian clinical practice guidelines for dementia (Guideline Adaptation Committee, 2016) and discussion with clinicians, the following interventions were considered for inclusion: pharmacological interventions, including antidepressants (excluding tricyclic antidepressants), cognitive enhancers (cholinesterase inhibitors or memantine), benzodiazepines, mood stabilizers (anticonvulsants/antimanics), antipsychotics, anxiolytics, analgesics (opioids, paracetamol), or melatonin; and non-pharmacological interventions, including functional analysis based interventions (behavior management), caregiver interventions 
(alone or dyadic), massage, recreation therapy, cognitive stimulation, exercise, music therapy, aromatherapy, or psychological therapy.

\section{OUTCOME}

Reviews reporting outcomes as measured on a recognized global BPSD scale, such as the Neuropsychiatric Inventory (NPI), Brief Psychiatric Rating Scale (BPRS), or the Behavior Assessment Tool (BAT) were included. Reviews were excluded if they only examined specific symptoms, such as agitation or depression as the outcome as this does not provide a measure of overall BPSD.

\section{Search strategy and selection of included studies}

The Cochrane Database of Systematic Reviews, the Database of Abstracts of Reviews of Effect (DARE), MEDLINE (including in process and other non-indexed citations), EMBASE, and PsycINFO were searched between the year 2000 and September 2015. The MEDLINE search strategy is included in the online supplementary information; this strategy was adapted accordingly for the other databases.

We identified and selected existing systematic reviews for inclusion and accepted these systematic reviews as complete. Our methods were consistent with that described in the Cochrane Handbook for Systematic Reviews of Interventions (Higgins and Green, 2011). We did not repeat the searches, determine eligibility or assess risk of bias for individual studies, or search for additional trials.

Two authors (SMD and SLH) independently assessed citations based on the title and abstracts. Irrelevant articles were excluded and potentially eligible articles were categorized by intervention. Full-text articles for any systematic reviews that were identified as potentially meeting the eligibility criteria were retrieved and assessed against the eligibility criteria by the same two authors. Reviews were classified by interventions (e.g. antipsychotics) and discussion occurred between the two authors regarding the most appropriate systematic review to include (based on the most recent and highest quality review). Reviews were required to have an AMSTAR rating of five or greater to be included. Reviews that overlapped with the most recent and comprehensive review were excluded so that studies were not double counted. Any discrepancies were resolved by consensus or by consulting a third author (KL).

\section{Data collection and analysis}

DATA EXTRACTION

Using a predefined data collection form, the following data were extracted from each paper: author details, title and year of the review, number of studies included, search date, and details of data from included RCTs (types of participants included, description of intervention, comparison, global BPSD definition and results, summary adverse event data). If the systematic review included data from RCTs and also other study designs, data were only extracted for the RCTs. Where a systematic review considered more than one intervention, only the data relevant to the intervention included in this overview were extracted. Where RCTs of studies against a number of comparators were included, data were extracted only for the placebo/usual care controlled RCTs.

\section{QUALITY ASSESSMENT}

Two authors independently assessed the quality of the included reviews using the AMSTAR (a measurement tool to assess systematic reviews) checklist (Shea et al., 2007). The overall quality of evidence for each intervention was assessed using the Grades of Recommendation, Assessment, Development, and Evaluation (GRADE) approach (Guyatt et al., 2011). Independent assessment was completed by two authors (SMD and SLH). The Cochrane Collaboration recommends adopting the GRADE approach to evaluate the quality of evidence reported in systematic reviews. This approach considers the risk of bias of included studies, directness of evidence, heterogeneity and precision of results and the risk of publication bias. The item for risk of bias includes assessment of methodological quality within the included RCTs, such as adequacy of blinding, allocation concealment and completeness of follow-up. Directness of evidence considers the applicability of the patients, interventions, comparator and outcomes. Heterogeneity (or inconsistency) addresses the degree of variation in effect size between the included studies. Precision of results considers the imprecision in the overall effect estimate, and thus is based upon the total sample size in the review. The risk of publication bias can generally only be assessed when there are sufficient studies included to enable assessment of this item. We used the GRADE assessment by the review authors where this had been conducted, consistent with Cochrane guidelines for overviews that recommend quality assessment should be based on assessments reported in the included systematic reviews (Higgins and Green, 2011). 


\section{DATA SYNTHESIS}

The standardized mean difference (SMD) from the review was extracted, when a meta-analysis reported this. If a mean difference was reported, we calculated the SMD to enable comparison of effect estimates across different interventions. If a review included non-RCTs or studies with a comparator other than a placebo or usual care then we extracted data only for the studies which met the inclusion criteria and a SMD was calculated. We did not perform a meta-analysis where the review authors did not pool data due to heterogeneity. Where a SMD was able to be determined, this was summarized graphically and a narrative synthesis of the results provided. Data were not displayed in the graphical representation for comparison to other interventions if there were $<50$ participants in total. All analyses were completed in Review Manager 5.3. (Cochrane Collaboration, 2014)

\section{Results}

The database searches retrieved 4,734 citations. After exclusion of duplicates, 1,149 citations from the pharmacological searches and 1,346 citations from the non-pharmacological searches were screened against the inclusion criteria independently by two reviewers. The study selection process is shown in Figure 1. Fifteen systematic reviews were included (Table 1 ). Two reviews were included for antidepressants; one reviewed studies of antidepressants for the treatment of depression (Nelson and Devanand, 2011) and the second reviewed antidepressants for the treatment of agitation or psychosis (Seitz et al., 2011). The summary of the pooled estimates of effect are summarized in Figure 2. The effects of five interventions are summarized narratively only (Table 2 ). These are of (a) aromatherapy (Forrester et al., 2014), (b) melatonin (Jansen et al., 2011), (c) dyadic caregiver interventions (Van't Leven et al., 2013), (d) reminiscence therapy interventions (Woods et al., 2005) for which a pooled estimate of the SMD could not be obtained due to heterogeneity, and (e) antidepressants for depression (Nelson and Devanand, 2011), where only a single study (44 participants) reported global BPSD outcomes. A list of key excluded reviews with reasons is provided in the supplementary material. No reviews were included for massage or anxiolytics as no review of RCTs reporting an outcome of global BPSD of adequate quality (AMSTAR > 4/11) was identified.

\section{Characteristics of the included reviews}

Table 1 summarizes the characteristics of the included reviews. One of the reviews examined more than one intervention and only data for the interventions included in this overview were extracted (Seitz et al., 2013). Eight of the included reviews examined non-pharmacological interventions and seven examined pharmacological interventions.

Fourteen of the 15 reviews included people with any type of dementia and one review included people with Alzheimer's disease. The mean age of participants was approximately 70-85 years old. The severity of dementia in the study participants ranged widely, from mild to severe.

\section{Methodological quality}

All included systematic reviews scored $\geq 5$ on the AMSTAR checklist (scores 5-8: $n=6$ and scores $\geq 9: n=9)$. Eight of nine reviews that scored $\geq 9$ on the AMSTAR checklist were Cochrane reviews. The inter-rater agreement is shown in the supplementary table (available as supplementary material attached to the electronic version of this paper at www.journals.cambridge.org/jid_IPG).

The quality of the evidence was higher for a greater proportion of the pharmacological interventions (for details see GRADE assessments provided in the supplementary materials). The overall quality of the evidence was rated as very low for three non-pharmacological interventions (exercise, aromatherapy, and reminiscence therapy) and one pharmacological intervention (sertraline); low for three non-pharmacological and three pharmacological interventions; moderate for two non-pharmacological and two pharmacological interventions, and high for four pharmacological interventions.

\section{Effects of interventions for BPSD}

In general, estimated effect sizes were very small $(<0.1)$ to small $(<0.4)$, with the exception of music therapy (low quality of evidence) (Figure 2).

NON-PHARMACOLOGICAL INTERVENTIONS

Two non-pharmacological interventions significantly reduced measures of global BPSD (Figure 2). Functional analysis-based interventions had an estimated 0.1 reduction in BPSD based on moderate quality evidence (12 studies, 1551 participants, SMD $-0.10,95 \%$ CI -0.20 to 0.00 ) (Moniz Cook et al., 2012). This effect was only found post-intervention and it was not significant at six-month follow-up after the intervention had ceased (4 studies, SMD 0.00, 95\% CI -0.16 to $0.16)$. Music therapy had a moderate effect size (SMD $-0.49,95 \%$ CI -0.82 to -0.17 ) based on low-quality evidence (Ueda et al., 2013). 


\section{PRISMA 2009 Flow Diagram}
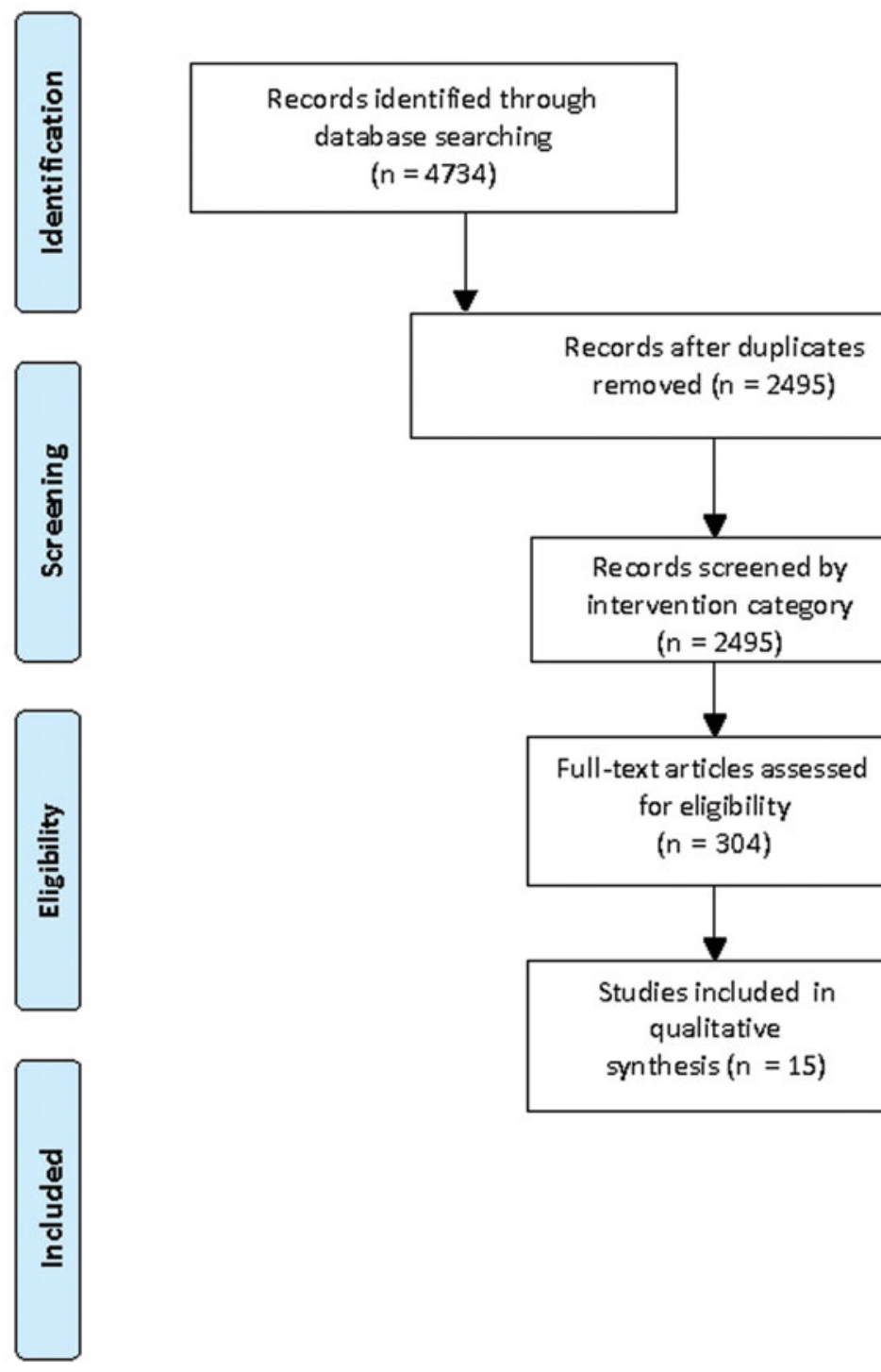

Records excluded

$(\mathrm{n}=2191)$

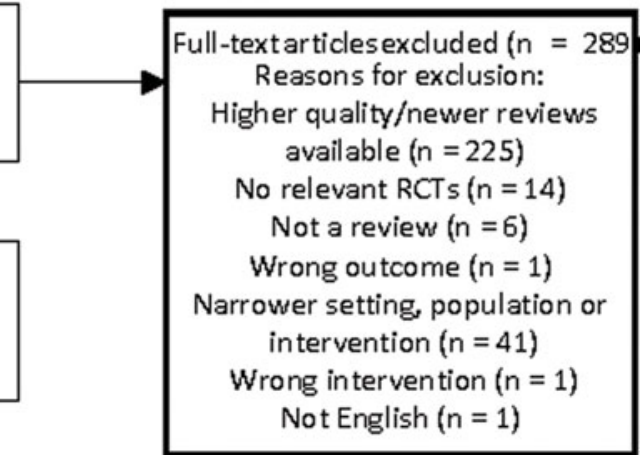

From: Moher D, Liberati A, Tetzlaff J, Altman DG, The PRISMA Group (2009). Preferred Reporting tems for Systematic Reviews and MetaAnalyses: The PRISMA Statement. PLOS Med 6(7): e1000097. doi:10.1371/journal.pmed1000097

For more in fornation, visit urrur.pris ma-statement.org.

Figure 1. (Colour online) Screening and selection of articles for inclusion in the review.

Three non-pharmacological interventions were not represented in Figure 2 and are summarized in Table 2. A review of aromatherapy (Forrester et al., 2014) reported outcomes from two studies; one study found a significant effect in favor of aromatherapy (Ballard et al., 2002, 71 participants), whereas the other found no significant difference (Burns et al., 2011, 63 participants). The authors concluded that there was insufficient evidence for clear conclusions to be drawn about the effectiveness of aromatherapy in dementia.

A review of dyadic caregiver interventions for people living with dementia in the community; six (806 participants) of the eight studies $(1,015$ 


\begin{tabular}{|c|c|c|c|c|c|c|}
\hline REVIEW & $\begin{array}{l}\text { DATE OF } \\
\text { SEARCH }\end{array}$ & $\begin{array}{l}\text { POPULATION CRITERIA, AGE } \\
\& \text { DEMENTIA SEVERITY OF } \\
\text { INCLUDED STUDIES. }\end{array}$ & INTERVENTION & COMPARISON & $\begin{array}{l}\text { OUTCOMES } \\
\text { (MEASUREMENT } \\
\text { SCALES USED) }\end{array}$ & $\begin{array}{l}\text { QUALITY } \\
\text { APPRAISAL } \\
\text { (AMSTAR) }\end{array}$ \\
\hline $\begin{array}{l}\text { Non-pharmacolc } \\
\text { Cook et al. } \\
\quad(2012)\end{array}$ & $\begin{array}{l}\text { cal interventions } \\
\text { March } 2011\end{array}$ & $\begin{array}{l}\text { Dementia of any type with BPSD } \\
\text { receiving support or treatment } \\
\text { from mental health workers, } \\
\text { care staff, family, or other } \\
\text { caregivers. } \\
\text { Mean age } 74.8-85 \text {. } \\
\text { Mean MMSE 12.6-16.8. }\end{array}$ & $\begin{array}{l}\text { Functional analysis-based } \\
\text { interventions } \\
\text { (formulation-led } \\
\text { individualised } \\
\text { interventions aimed at } \\
\text { identifying unmet } \\
\text { need/cause/antecedents } \\
\text { and consequences of } \\
\text { behaviour "ABCs") }\end{array}$ & Usual care & $\begin{array}{l}\text { Frequency of } \\
\text { problem } \\
\text { behaviours (change } \\
\text { in PC, RAGE, } \\
\text { RMBPC, CMAI, } \\
\text { MBCL) }\end{array}$ & $11 / 11$ \\
\hline $\begin{array}{l}\text { Forbes et al. } \\
\quad(2015)\end{array}$ & October 2013 & $\begin{array}{l}\text { Majority } \geq 65 \text { years, dementia } \\
\text { diagnosis. } \\
\text { Mean age } 83 \\
\text { Mean MMSE: } 8.8 \text {. }\end{array}$ & $\begin{array}{l}\text { Exercise programmes, any } \\
\text { length }\end{array}$ & $\begin{array}{c}\text { Usual care or social } \\
\text { contact/activities. }\end{array}$ & $\begin{array}{l}\text { Neuropsychiatric } \\
\text { symptoms (NPI) }\end{array}$ & $10 / 11$ \\
\hline $\begin{array}{l}\text { Forrester et al. } \\
\quad(2014)\end{array}$ & January 2013 & $\begin{array}{l}\text { Dementia diagnosis, any type and } \\
\text { severity. } \\
\text { Nursing home residents with } \\
\text { clinically significant agitation } \\
\text { Mean age } 78 \text { to } 85 \text {. }\end{array}$ & $\begin{array}{l}\text { Aromatherapy (using } \\
\text { fragrance from plants), } \\
\text { any dose, frequency, or } \\
\text { fragrance }\end{array}$ & $\begin{array}{l}\text { Placebo } \\
\text { aromatherapy }\end{array}$ & $\begin{array}{l}\text { Behavioural } \\
\text { symptoms } \\
\text { (NPI-total scores) }\end{array}$ & $9 / 11$ \\
\hline $\begin{array}{l}\text { Orgeta et al. } \\
\quad(2014)\end{array}$ & January 2013 & $\begin{array}{l}\text { Dementia, any type or MCI } \\
\text { Mean age } 76-78 \\
\text { Mean MMSE } 20.9 ; \text { MMSE } \geq 20\end{array}$ & Psychological treatment & Usual care & $\begin{array}{l}\text { Neuropsychiatric } \\
\text { symptoms (NPI, } \\
\text { NPI-Q) }\end{array}$ & $9 / 11$ \\
\hline $\begin{array}{l}\text { Ueda et al. } \\
\quad(2013)\end{array}$ & February 2011 & $\begin{array}{l}\text { Dementia diagnosis, any type } \\
\text { Mean age } 75-86 \text {. } \\
\text { Severity mild to severe. }\end{array}$ & Music therapy & Usual care & $\begin{array}{l}\text { Behaviour (change, } \\
\text { BSAD scale, NPI, } \\
\text { NPI-Q, CMAI, } \\
\text { ESEP) }\end{array}$ & $7 / 11$ \\
\hline
\end{tabular}

Non-pharmacological interventions

Cook et al. March 2011

unctional analysis-based

individualised

ntions aimed at

dentifying unme

behaviour "ABCs") 
Table 1. Continued

\begin{tabular}{|c|c|c|c|c|c|c|}
\hline REVIEW & $\begin{array}{l}\text { DATE OF } \\
\text { SEARCH }\end{array}$ & $\begin{array}{l}\text { POPULATION CRITERIA, AGE } \\
\& \text { DEMENTIA SEVERITY OF } \\
\text { INCLUDED STUDIES. }\end{array}$ & INTERVENTION & COMPARISON & $\begin{array}{l}\text { OUTCOMES } \\
\text { (MEASUREMENT } \\
\text { SCALES USED) }\end{array}$ & $\begin{array}{l}\text { QUALITY } \\
\text { APPRAISAL } \\
\text { (AMSTAR) }\end{array}$ \\
\hline $\begin{array}{l}\text { Van't Leven } \\
\text { et al. }(2013)\end{array}$ & January 2012 & $\begin{array}{l}\text { Community-dwelling people with } \\
\text { dementia and their caregivers. } \\
\text { Age not reported. } \\
\text { Mean MMSE 11.0-20.6. }\end{array}$ & $\begin{array}{l}\text { Dyadic psychosocial } \\
\text { interventions }\end{array}$ & Usual care & $\begin{array}{l}\text { Behavioural } \\
\text { problems } \\
\text { (Unclear) }\end{array}$ & $5 / 11$ \\
\hline $\begin{array}{l}\text { Woods et al. } \\
\text { (2012) }\end{array}$ & $\begin{array}{l}\text { December } \\
2011\end{array}$ & $\begin{array}{l}\text { Dementia diagnosis, any sub-type } \\
\text { and severity. } \\
\text { Mean age } 76-853 \text {. } \\
\text { MMSE range } 18-25 \text {, mean } 20 \\
\text { and moderate to severe } \\
\text { impairment. }\end{array}$ & $\begin{array}{l}\text { Cognitive stimulation } \\
\text { aimed at general } \\
\text { enhancement of cognitive } \\
\text { and social functioning. }\end{array}$ & $\begin{array}{l}\text { No treatment, } \\
\text { standard treatment } \\
\text { or placebo. }\end{array}$ & $\begin{array}{l}\text { Behaviour, problem } \\
\text { (change in BPRS, } \\
\text { MOSES, NPI) }\end{array}$ & $10 / 11$ \\
\hline $\begin{array}{l}\text { Woods } \\
\text { et al.(2005) }\end{array}$ & May 2004 & $\begin{array}{l}\text { Dementia of any type or cognitive } \\
\text { impairment } \\
\text { Mean age } 76.3-85.7 \\
\text { dementia or moderate to severe } \\
\text { cognitive functioning }\end{array}$ & $\begin{array}{l}\text { Reminiscence therapy. } \\
\text { Minimum } 4 \text { weeks, } 6 \\
\text { sessions, led by } \\
\text { professional staff or } \\
\text { trained care-workers }\end{array}$ & $\begin{array}{l}\text { Control activity or } \\
\text { no treatment }\end{array}$ & $\begin{array}{l}\text { Behaviour } \\
\text { post-treatment } \\
\text { (change in CAPE, } \\
\text { PBRS, } \\
\text { MDS-ADL) }\end{array}$ & $9 / 11$ \\
\hline \multicolumn{7}{|c|}{ Pharmacological interventions } \\
\hline $\begin{array}{l}\text { Jansen et al. } \\
\text { (2011) }\end{array}$ & June 2009 & $\begin{array}{l}\text { Dementia of any severity or type } \\
\text { Mean age: } 77-88 \\
\text { MMSE: moderate }\end{array}$ & $\begin{array}{l}\text { Melatonin, orally } \\
\text { administered, for } \\
\text { managing cognitive, } \\
\text { behavioural (excluding } \\
\text { sleep) and mood } \\
\text { disturbances. }\end{array}$ & $\begin{array}{l}\text { Placebo or no } \\
\text { treatment }\end{array}$ & $\begin{array}{l}\text { Psychopathological } \\
\text { behaviors (change } \\
\text { in NPI, ADAS-non } \\
\text { cog, NPI-Q, at 4-7 } \\
\text { weeks) }\end{array}$ & $9 / 11$ \\
\hline $\begin{array}{r}\text { Ma et al. } \\
(2014)\end{array}$ & June 2013 & $\begin{array}{l}\text { Dementia of any type } \\
\text { Mean age } 77-83 \text {. } \\
\text { Severity not reported }^{\text {a }}\end{array}$ & $\begin{array}{l}\text { Second generation } \\
\text { antipsychotics }\end{array}$ & Placebo & $\begin{array}{l}\text { NPI (change from } \\
\text { baseline) }\end{array}$ & $9 / 11$ \\
\hline $\begin{array}{l}\text { Nelson and } \\
\text { Devanand } \\
(2011)\end{array}$ & May 2010 & $\begin{array}{l}\text { Diagnosis of dementia and } \\
\text { depression. } \\
\text { Mean age: } 768 \\
\text { Mean HDRS: } 23 \\
\text { Dementia severity not reported }\end{array}$ & $\begin{array}{l}\text { Antidepressants for } \\
\text { dementia and } \\
\text { depression }^{\mathrm{b}}\end{array}$ & Placebo & NPI (response rates) & $7 / 11$ \\
\hline
\end{tabular}


Table 1. Continued

\begin{tabular}{|c|c|c|c|c|c|c|}
\hline REVIEW & $\begin{array}{l}\text { DATE OF } \\
\text { SEARCH }\end{array}$ & $\begin{array}{l}\text { POPULATION CRITERIA, AGE } \\
\& \text { DEMENTIA SEVERITY OF } \\
\text { INCLUDED STUDIES. }\end{array}$ & INTERVENTION & COMPARISON & $\begin{array}{l}\text { OUTCOMES } \\
\text { (MEASUREMENT } \\
\text { SCALES USED) }\end{array}$ & $\begin{array}{l}\text { QUALITY } \\
\text { APPRAISAL } \\
\text { (AMSTAR) }\end{array}$ \\
\hline $\begin{array}{l}\text { Pieper et al. } \\
\text { (2013) }\end{array}$ & March 2012 & $\begin{array}{l}\text { Dementia diagnosis, any type. } \\
\text { Mean age: intervention arm: } 85 \text {, } \\
\text { control arm } 87 \text {. } \\
\text { Severity: moderate to severe. }\end{array}$ & $\begin{array}{l}\text { Interventions targeting a } \\
\text { reduction in the person's } \\
\text { pain or distress and/or } \\
\text { behaviour. Includes pain } \\
\text { medication, analgesia, } \\
\text { and drug therapy. }\end{array}$ & Usual care & $\begin{array}{l}\text { Behaviour (NPI-NH } \\
\text { total at endpoint) }^{c}\end{array}$ & $7 / 11$ \\
\hline $\begin{array}{l}\text { Seitz et al. } \\
\quad(2011)\end{array}$ & October 2011 & $\begin{array}{l}\text { Dementia of any type or severity, } \\
\text { without concomitant major } \\
\text { depressive disorder } \\
\text { Mean age: NR } \\
\text { MMSE: } 8-23 \text {. }\end{array}$ & $\begin{array}{l}\text { Antidepressants with } \\
\text { primary outcome } \\
\text { treatment of psychosis, } \\
\text { agitation or other NPS. }\end{array}$ & Placebo & $\begin{array}{l}\text { Behaviour (NPI } \\
\text { change in total } \\
\text { score) }\end{array}$ & $11 / 11$ \\
\hline $\begin{array}{l}\text { Seitz et al. } \\
\quad(2013)\end{array}$ & February 2011 & $\begin{array}{l}\text { Dementia of any type, }>50 \% \text { in } \\
\text { residential care. } \\
\text { Mean age: } 84-85 \\
\text { Mean MMSE: } 7-11\end{array}$ & $\begin{array}{l}\text { Mood stabilizers } \\
\quad(\text { anticonvulsants })^{\mathrm{d}}\end{array}$ & Placebo & $\begin{array}{l}\text { Neuropsychiatric } \\
\text { symptoms (change } \\
\text { in BPRS total } \\
\text { score) }\end{array}$ & $7 / 11$ \\
\hline $\begin{array}{r}\text { Tan et al. } \\
(2014)\end{array}$ & $\begin{array}{l}\text { November } \\
2013\end{array}$ & $\begin{array}{l}\text { Probable or possible Alzheimer's } \\
\text { disease. } \\
\text { Mean age } 73-86 \\
\text { MMSE range: } 10-19\end{array}$ & $\begin{array}{l}\text { Cholinesterase inhibitors } \\
\text { (donepezil, galantamine, } \\
\text { rivastigmine) and } \\
\text { memantine }\end{array}$ & Placebo & $\begin{array}{l}\text { Behaviour (change in } \\
\text { NPI scale) }\end{array}$ & $7 / 11$ \\
\hline
\end{tabular}

Abbreviations: ADAS $=$ Alzheimer's Disease Assessment Scale; AMSTAR $=$ Assessing the methodological quality of systematic reviews; BAT $=$ Behaviour Assessment Tool; BPRS $=$ Brief Psychiatric Rating Scale; BPSD = Behavioural and psychological symptoms of dementia; BSAD = Behavioural Symptomatology in Alzheimer's Disease scale; CAPE = Clifton Assessment Procedures for the Elderly; CMAI = Cohen-Mansfield Agitation Inventory; ESEP = Evaluation Scale for Elderly Patients; HDRS = Hamilton Depression Rating Scale; MBCL = Memory \& Procedures for the Elderly; CMAI = Cohen-Mansfield Agitation Inventory; ESEP = Evaluation Scale for Elderly Patients; HDRS = Hamilton Depression Rating Scale;
Behaviour Checklist; MCI= mild cognitive impairment; MMSE = Mini-Mental State Examination; MOSES = Multidimensional Observation Scale for Elderly Subjects;

Behaviour Checklist; $\mathrm{MCI}=$ mild cognitive impairment; MMSE= Mini-Mental State Examination; MOSES = Multidimensional Observation Scale for Elderly Subjects;
NPI = Neuropsychiatric Inventory; NPI/NH = Neuropsychiatric Inventory /Nursing Home; NPI-Q = Neuropsychiatric Inventory-Brief Questionnaire Form; NPS = neuropsychiatric symptoms; NR = not reported; PC = Problem Checklist; RAGE = Rating Scale for Aggressive Behaviour in the Elderly; RMBPC = Revised Memory and Behaviour Problem Checklist. a Severity of dementia not reported, however the majority of trials included patients with psychosis and/or other behavioural symptoms.

b Single included RCT reporting global BPSD outcomes versus placebo was for sertraline hydrochloride.

${ }^{\mathrm{c}}$ Data extracted from original RCT as suitable data for calculation of SMD not reported in review.

${ }^{\mathrm{d}}$ Only divalproex sodium included as not considered clinically appropriate to pool the different pharmacological agents; most evidence existed for divalproex (two RCTs). 
Number of studies

Intervention

(participants)

$\operatorname{SMD}(95 \% \mathrm{CI})$

$\operatorname{SMD}(95 \% \mathrm{Cl})$

GRADE

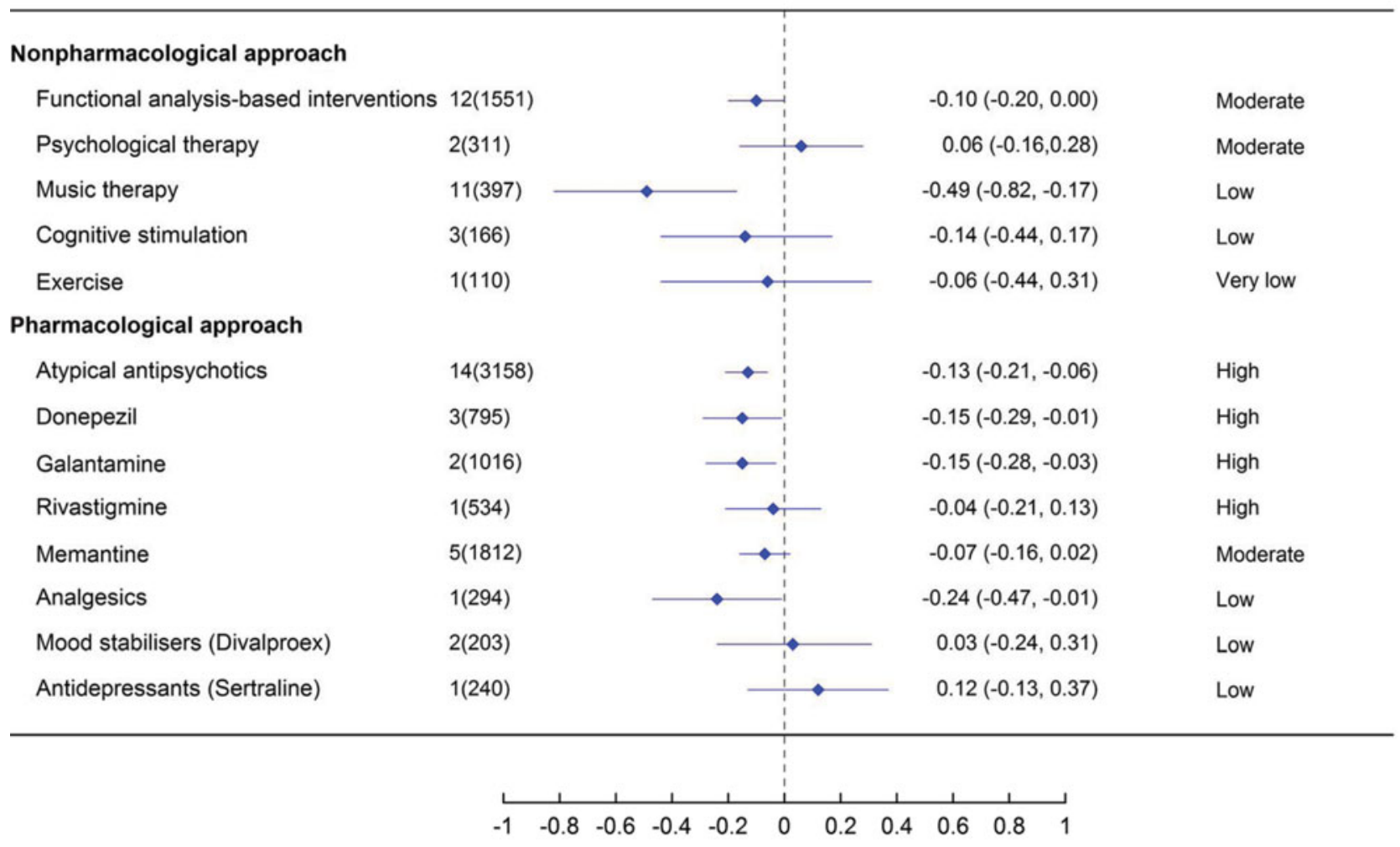

Figure 2. (Colour online) The effect of alternative treatments for the management of behavioural and psychological symptoms of dementia on global BPSD measures. Note: antidepressant estimate of effect is from a review of antidepressants for the treatment of agitation and psychosis. Abbreviations: $\mathrm{Cl}=$ confidence interval; SMD = standardized mean difference.

participants) did not demonstrate a statistically significant improvement in BPSD (Van't Leven et al., 2013).

A review of reminiscence therapy was included as the highest quality review of recreational interventions identified (Woods et al., 2005). Pooled data from two studies demonstrated a significant improvement in global BPSD, however only 20 participants are included in this analysis. One larger study (66 participants) reporting outcomes measured on a different scale found no significant effect. The quality of evidence overall for reminiscence therapy was considered very low.

\section{Pharmacological interventions}

Four of the pharmacological interventions demonstrated a significant reduction in global BPSD. Two anticholinesterase inhibitors had a small, but statistically significant effect (donepezil $10 \mathrm{mg}$ : three studies, 795 participants, SMD $-0.15,95 \%$ CI -0.29 to -0.01 and galantamine $24 \mathrm{mg}$ : two studies, 1,016 participants, SMD $-0.15,95 \%$ CI -0.28 to -0.03 ) based on high quality evidence
(Tan et al., 2014). The quality of available evidence was greatest for atypical antipsychotics and a small but statistically significant effect on reducing BPSD was observed (14 studies, 3,158 participants, SMD $-0.13,95 \%$ CI -0.21 to -0.06 ) (Ma et al., 2014). Pain management with analgesics (using a stepped protocol) also had a significant effect on reducing global BPSD, however the quality of the evidence was considered low and was based on a single RCT (294 participants, SMD $-0.24,95 \%$ CI -0.47 to -0.01) (Pieper et al., 2013). There was no statistically significant reduction in global BPSD with the other pharmacological interventions.

The effect estimate for two pharmacological interventions was not summarized in Figure 2 and is presented in Table 2. A review of antidepressants for people with dementia and concomitant depression included one study (44 participants) that reported global BPSD outcomes. No significant effect was observed (SMD $-0.25,95 \% \mathrm{CI}-0.85$ to 0.35 ; very low quality evidence) (Nelson and Devanand, 2011). A review of melatonin reported a significant reduction in BPSD based on pooled data from two studies of melatonin at four to seven 
Table 2. Global BPSD outcomes for included systematic reviews not summarized as pooled standardized mean difference (SMD)

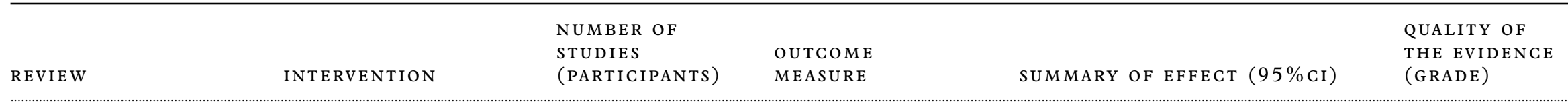

Non-pharmacological interventions

Forrester et al. (2014) Aromatherapy

$2(134)$

NPI mean change
Data were not pooled due to
heterogeneity $\left(I^{2}=89 \%\right)$ Effects
for each study: $\mathbf{M D}-\mathbf{1 5 . 8 0}$
$(-24.40$ to -7.20$)$ MD 2.80
$(-5.84$ to 11.44$)$

Very low

\begin{tabular}{|c|c|c|}
\hline Leven et al. (2013) & $\begin{array}{l}\text { Dyadic caregiv } \\
\text { interventions }\end{array}$ & $8(101$ \\
\hline
\end{tabular}

Data were not pooled due to

heterogeneity

Effects for each study:

SMD -0.66 (-1.20, -0.12)

SMD $0.27(-0.17,0.72)$

SMD $-0.05(-0.33,0.24)$

SMD $0.13(-0.14,0.40)$

SMD $-0.10(-0.43,0.24)$

SMD $-0.36(-0.88,0.16)$

SMD $-0.51(-0.83,-0.19)$

SMD $-0.28(-0.63,0.07)$

Woods et al. (2005)

Reminiscence therapy

$3(86)$

Change in behaviour post-treatment

Data were not pooled due to

heterogeneity

Very low

Effects for each outcome measure:

MD $7.61(2.42,12.80)^{a, b}$

(CAPE-Behaviour)

MD $2.20(-11.84,16.24)^{\mathrm{a}}(\mathrm{BPRS})$

MD $0.42(-4.91,5.75)$

(MDS-ADL)

Pharmacological interventions

Nelson and Devanand

Antidepressants for

$1(44)$

NPI (response rates)

SMD $-0.25(-0.85$ to 0.35$)$

Very low

Jansen et al. (2011)

Melatonin

$2(121)$

Psychopathological behaviors (change

in NPI, ADAS-non

MD $-3.48,95 \%$ CI -4.89 to -2.07

Moderate

Statistically significant effects are highlighted in bold.

Abbreviations: ADAS = Alzheimer's Disease Assessment Scale; BPRS = Brief Psychiatric Rating Scale; CAPE $=$ Clifton Assessment Procedures for the Elderly; CI = confidence interval; GRADE $=$ Grades of Recommendation, Assessment, Development and Evaluation; MD = mean difference; NPI = Neuropsychiatric Inventory; NPI-Q = Neuropsychiatric Inventory-Brief

Questionnaire Form; SMD = standardized mean difference.

a One study $(N-10)$ included in both outcomes. ${ }^{b}$ Total $N=20$ for this outcome. 
weeks (MD $-3.48,95 \% \mathrm{CI}-4.89$ to $-2.07 ; 121$ participants) (Jansen et al., 2011). Another study in the review found no significant effect on BPSD at two years follow-up (MD $-2.70,95 \% \mathrm{CI}-7.70$ to $2.30 ; 19$ participants). The quality of the evidence was rated moderate; however the low number of participants indicated a serious risk of bias in terms of the precision of the estimates.

\section{ADVERSE EVENTS}

Of the eight non-pharmacological interventions included in this overview, six of the reviews reported on adverse events and none of these reviews reported any significant increased risk of adverse events due to the intervention (Table 3). All of the reviews which examined pharmacological interventions reported on adverse events. The reviews for memantine, antidepressants (sertraline), and mood stabilizers (divalproex) also reported no significant increased risk of adverse events due to the intervention (Seitz et al., 2011; Seitz et al., 2013; Tan et al., 2014). Melatonin was also not associated with any increased risk of adverse events, but the authors did note a significant worsening of mood after 12 months with melatonin compared to placebo (Jansen et al., 2011). Analgesics had very few reported adverse events (three participants were excluded because of drowsiness and nausea) and a similar loss to follow-up in intervention and control group, based on a single RCT (Pieper et al., 2013). Atypical antipsychotics were reported to be associated with an increased risk of many adverse events including somnolence, extrapyramidal symptoms, cerebrovascular adverse events, urinary tract infections, edema, gait abnormality, and death compared to a placebo (Ma et al., 2014). Also, cholinesterase inhibitors (donepezil, galantamine, and rivastigmine) were associated with an increased risk of several adverse events including dizziness, headaches, nausea, vomiting, diarrhea, and anorexia compared to a placebo (Tan et al., 2014).

\section{Discussion}

BPSD significantly impact on the quality of life of both people living with dementia and their caregivers (Hurt et al., 2008). Management of BPSD is also a significant workplace issue in community, hospital and residential aged care settings in terms of adequately training staff in prevention, de-escalation and management techniques. Multiple reviews and individual trials have been published examining the effectiveness of various interventions for BPSD and the wide range of information sources can provide conflicting information when used to inform practice. The current review attempts to provide an overview of the evidence base and compare the effectiveness of a range of interventions, by summarizing existing systematic reviews.

This overview summarizes RCT evidence for the effects of 17 different interventions for the management of BPSD. A statistically significant effect in improving global BPSD was seen for functional analysis-based interventions, music therapy, analgesics, melatonin, donepezil, galantamine, and atypical antipsychotics. The low-quality evidence supporting the effectiveness of music therapy and analgesics indicates some uncertainty in these findings. Although the melatonin review reported a significant reduction in BPSD in pooled data from two studies, there was also reported to be a significant worsening of mood at 12 months (Jansen et al., 2011). Given these conflicting findings, overall the evidence for melatonin is considered insufficient to conclude whether or not it is effective in the treatment of BPSD. Importantly, the non-pharmacological approaches have a similar effect size for treating global BPSD to the pharmacological approaches. However, the non-pharmacological approaches did not have any reported adverse events, whereas, atypical antipsychotics and cholinesterase inhibitors were reported to have an increased risk of many adverse events in comparison with placebo.

Internationally, clinical practice guidelines for dementia recommend that non-pharmacological approaches for the management of BPSD should be used as a first line approach and that pharmacological treatments should be used in addition to, not as a replacement for, non-pharmacological approaches (Azermai et al., 2012; Guideline Adaptation Committee, 2016). While the quality of the evidence base for non-pharmacological approaches is generally lower than for pharmacological treatments, it is noteworthy that the estimates of effect size of these interventions is similar to that of the pharmacological treatments and that the non-pharmacological treatment are not associated with any adverse events. The estimated effect sizes for antipsychotics, donepezil or galantamine were $0.03-0.05$ greater than that for functional analysis-based interventions (0.13 or 0.15 vs. 0.10 ). However, functional analysisbased interventions have a significant impact on global BPSD based on moderate quality evidence, indicating that this intervention should be used as first line treatment whenever possible, due to the lack of possible side effects (Moniz Cook et al., 2012). Such interventions include the antecedent (triggers), behavior description and consequence approach (ABC approach) and involves analyzing 
Table 3. Adverse events of the interventions, as reported in the included reviews

INTERVENTION (REVIEW

FIRST AUTHOR, YEAR)

Non-pharmacological interventions

Functional-analysis based interventions (Moniz Cook, 2012)

Psychological therapy

(Orgeta et al., 2014)

Music therapy (Ueda, 2013)

Cognitive stimulation

(Woods et al., 2012)

Exercise (Forbes, 2015)

Aromatherapy (Forrester, 2014)

Dyadic caregiver interventions (Van't

Leven, 2013)

Reminiscence therapy

(Woods, 2005)

Pharmacological interventions

Atypical antipsychotics

(Ma, 2014)

Cholinesterase inhibitors (Tan, 2014)

Memantine (Tan, 2014)

Analgesics (Pieper, 2013)

Mood stabilizers

(Divalproex) (Seitz, 2013)

Melatonin (Jansen, 2011)

Antidepressants

(Sertraline) (Seitz, 2011)
ADVERSE EVENTS DESCRIBED IN THE INCLUDED REVIEWS

The review states "no indications from the outcome measures of the 18 studies included in the current analysis of any harm or distress to participants with dementia."

"Psychological treatments for people with dementia appear to be safe, with no adverse events reported in the literature."

No data on adverse events were reported.

The review states "there were no reported side effects or adverse effects of any of the cognitive stimulation interventions."

None of the included trials which reported on adverse events reported any serious adverse events that could be attributed to the exercise intervention.

No difference in adverse events of aromatherapy compared to placebo.

No data on adverse events were reported.

The review states "No harmful effects were identified."

Significantly higher risk for somnolence, extrapyramidal symptoms, cerebrovascular adverse events, urinary tract infections, edema, gait abnormality, and death compared to placebo. Some adverse effects had incidence rates of $>5 \%$ and were observed in most trials.

Dropouts from the trials for any reason were significantly greater for $12 \mathrm{mg}$ daily rivastigmine and $32 \mathrm{mg}$ daily galantamine than with placebo. Dropouts due to adverse events were significantly higher for $10 \mathrm{mg}$ daily donepezil, $12 \mathrm{mg}$ daily rivastigmine, and $32 \mathrm{mg}$ daily galantamine compared to placebo.

The review states "Significant risks were reported for the following adverse events: dizziness and headache on $5 \mathrm{mg}$ daily donepezil; nausea, vomiting, diarrhea, and anorexia on $10 \mathrm{mg}$ daily donepezil; nausea, vomiting, diarrhea, anorexia, and dizziness on galantamine; and nausea, vomiting, diarrhea, anorexia, dizziness, and headache on rivastigmine."

Memantine was not significantly associated with more dropouts or adverse events.

Only one RCT which had very few reported adverse events (three participants were excluded because of drowsiness and nausea) and similar loss to follow-up in intervention and control group.

Similar or lower rates of withdrawals overall and withdrawals due to adverse events with divalproex compared to placebo in the two RCTs.

The review states "No reported adverse effects." However, the authors did state a significant worsening of mood after 12 months.

Only one RCT, no difference in withdrawal due to adverse events or withdrawal due to any causes in sertraline treated group compared to placebo. the cause or purpose behind a person's behavior, to produce a targeted strategy to address the behavior, rather than using a single, "one size fits all" approach. The efficacy of functional analysis-based interventions was not maintained at six month follow-up in this review and therefore functionalanalysis based interventions may not have a longterm beneficial effect. However, the long-term benefits of functional analysis based interventions warrants further research as the evidence at 6 months was only based on four studies rather than 12 which reported immediate effects postintervention.

Further research in the form of high quality randomised trials and systematic reviews measuring global BPSD outcomes is required for other non-pharmacological therapies including massage and recreation therapy (including reminiscence therapy) to enable assessment of their effectiveness and comparison to the existing alternatives. 
Antipsychotics are reported to be used widely in residential care and in people living with dementia despite repeated warnings about the associated harms (i.e. increased risk of cerebrovascular events and death in people living with dementia) (Douglas and Smeeth, 2008; Corbett and Ballard, 2012). The recent Beers criteria for potentially inappropriate medication use in older adults strongly recommend that antipsychotics for BPSD or delirium in dementia "should be avoided unless non-pharmacological interventions have failed or are not possible and the older adult is threatening substantial harm to self or others" (American Geriatrics Society Beers Criteria Update Expert Panel, 2015). While there are likely to be cases of severe BPSD where there is a risk of harm to the person living with dementia or others, for which alternative approaches may not be possible, the current review emphasizes the value and potential effectiveness of alternatives, given that the magnitude of effects is similar. It is noteworthy that the magnitude of effect seen with antipsychotics is not greater than that seen with donepezil or galantamine. Further, the greatest effect seen with any pharmacological intervention was that associated with a stepped analgesic approach and the greatest effect size for BPSD was seen for music therapy, although the quality of the evidence supporting these interventions is low, so additional studies are required to provide a better estimate of any effect size. Given the potential harms associated with the use of antipsychotics, these findings support recommendations that antipsychotics should be reserved for those with severe symptoms where non-pharmacological approaches have failed or are not feasible (Schneider et al., 2005).

It is likely that patients enrolled in the trials of different interventions may have been experiencing different symptoms with a variation in severity, and that this may influence the effectiveness of any treatment investigated. However, the information provided in the existing systematic reviews was generally inadequate to draw clear conclusions about this. Nevertheless, participants in the single trial of exercise had quite advanced dementia, (mean MMSE 8.8) and it is possible that this is a factor in the lack of effectiveness of exercise seen in this trial (Forbes et al., 2015).

While the advantage of this overview is that it provides a succinct summary of evidence across a range of interventions, one of the limitations is that this review was limited to reported outcomes of global BPSD and therefore it does not capture the effectiveness of these treatments on subdomains of BPSD symptoms such as depression, agitation or disinhibition. It is acknowledged that in many cases clinicians may need to target therapies to individual symptoms. However, the evidence provided here is mainly based on widely used scales for BPSD, such as the NPI. Similarly, the generalizability of findings in populations with Alzheimer's disease or mixed dementia subtypes to other types of dementia such as frontotemporal dementia is unknown. As this is an overview of existing systematic reviews, we accepted the inclusion criteria, ratings of quality, and metaanalytic methods of the authors of the included reviews and there is therefore the possibility of some inconsistency across the interventions. In addition, more recent trial evidence may be available for some interventions (e.g. for reminiscence therapy and melatonin) that would not be included in the reviews cited. None of the included reviews reported outcomes data as number needed to treat/harm. Future research should include this statistic to allow for a more complete comparison of intervention harms and effects. Furthermore, the majority of the included reviews did not provide summary data to show the exact numbers of participants with different types of dementia. The interventions searched for in this review were based on discussions with the Guidelines Adaptation Committee (2016) during the development of the Australian clinical practice guidelines for dementia; some more novel interventions may not have been included in the scope of the review.

\section{Conclusions}

Overall, this overview provides support for using the non-pharmacological approach of functionalanalysis based interventions as first line therapy for BPSD, due to the significant impact on global BPSD measures, moderate quality evidence and the lack of adverse events. Music therapy may also be effective in the management of BPSD; however, further high quality evidence would be useful to strengthen the support for its use. Many other non-pharmacological approaches require additional research to enable adequate evidence for the assessment of their effectiveness as alternative treatments. This overview highlighted that non-pharmacological approaches have similar effect sizes to pharmacological approaches, but with a lower risk of adverse events. This emphasizes the value in the clinical use of non-pharmacological approaches and these should be used as a first line treatment where possible. Where these have failed or are not appropriate for the individual, the benefits of cholinesterase inhibitors, not only for management of cognitive symptoms but also for BPSD, and the assessment and 
treatment of pain should be considered, although evidence supporting this is low. This overview provides further support for reserving the use of antipsychotics for severe cases of BPSD where there is a serious risk of harm to the person with dementia or others, given the increased risk of serious adverse events and the small magnitude of effect.

\section{Conflicts of interest}

This work was supported by the National Health and Medical Research Council (NHMRC) Partnership Centre on Dealing with Cognitive and Related Functional Decline in Older People (Grant no. GNT9100000). CW is an unpaid board member of Helping Hand Aged Care. MC has received funding from Eli Lilly paid to Flinders University for travel expenses to a start-up meeting on a sarcopenia pharmaceutical trial. No other disclosures to report.

\section{Description of authors' roles}

All authors contributed to planning the study, manuscript preparation, interpretation, and academic content. SMD and SLH independently reviewed and selected studies for inclusion. KL resolved any discrepancies in study selection. SLH, SMD, and KL conducted data extraction and checking. SMD, SLH, and KL conducted quality assessment.

\section{Acknowledgments}

The authors thank Enwu Liu for creating the graphic (Figure 2).

\section{Supplementary material}

To view supplementary material for this article, please visit https://doi.org/10.1017/ S1041610217002344

\section{References}

Alzheimer's Disease International (2009). World Alzheimer Report 2009.

Alzheimer's Disease International (2015). World Alzheimer Report 2015.

American Geriatrics Society Beers Criteria Update Expert Panel (2015). American geriatrics society 2015 updated beers criteria for potentially inappropriate medication use in older adults. Fournal of The American Geriatrics Society, 63, 2227-2246.
Azermai, M., Petrovic, M., Elseviers, M. M., Bourgeois, J., Van Bortel, L. M. and Vander Stichele, R. H. (2012). Systematic appraisal of dementia guidelines for the management of behavioural and psychological symptoms. Ageing Research Reviews, 11, 78-86.

Ballard, C. G., O'Brien, J. T., Reichelt, K. and Perry, E. K. (2002). Aromatherapy as a safe and effective treatment for the management of agitation in severe dementia: the results of a double-blind placebo-controlled trial with Melissa. Fournal of Clinical Psychiatry, 63, 553558.

Burns, A. et al. (2011). A double-blind placebo-controlled randomized trial of Melissa officinalis oil and donepezil for the treatment of agitation in Alzheimer's disease. Dementia and Geriatric Cognitive Disorders, 31, 158-164.

Cerejeira, J., Lagarto, L. and Mukaetova-Ladinska, E. B. (2012). Behavioral and psychological symptoms of dementia. Frontiers of Neurology, 3, 73.

Chen, Y., Briesacher, B. A., Field, T. S., Tjia, J., Lau, D. T. and Gurwitz, J. H. (2010). Unexplained variation across US nursing homes in antipsychotic prescribing rates. Archives of Internal Medicine, 170, 89-95.

Cochrane Collaboration (2014). RevMan. Informatics and knowledge management Department.

Corbett, A. and Ballard, C. (2012). Antipsychotics and mortality in dementia. American fournal of Psychiatry, 169, 7-9.

Douglas, I. J. and Smeeth, L. (2008). Exposure to antipsychotics and risk of stroke: self controlled case series study. BMF, 337, a1227.

Forbes, D., Forbes, S. C., Blake, C. M, Thiessen, E. J. and Forbes, S. (2015). Exercise programs for people with dementia. Cochrane Database of Systematic Reviews, 4, CD006489.

Forrester, L. T., Maayan, N., Orrell, M., Spector, A. E., Buchan, L. D. and Soares-Weiser, K. (2014). Aromatherapy for dementia. Cochrane Database of Systematic Reviews, 2, CD003150.

Guideline Adaptation Committee (2016). Clinical Practice Guidelines and Principles of Care for People with Dementia. Sydney: NHMRC Cognitive Decline Partnership Centre. Available at: http://www.clinicalguidelines.gov.au/portal/ 2503/clinical-practice-guidelines-and-principles-carepeople-dementia.

Guyatt, G. et al. (2011). GRADE guidelines: 1. Introduction-GRADE evidence profiles and summary of findings tables. Fournal of Clinical Epidemiology, 64, 383-394.

Higgins, J. and Green, S. (2011). Cochrane Handbook for Systematic Reviews of Interventions. London, UK: The Cochrane Collaboration.

Hurt, C. et al. (2008). Patient and caregiver perspectives of quality of life in dementia. An investigation of the relationship to behavioural and psychological symptoms in dementia. Dementia and Geriatric Cognitive Disorders, 26, 138-146.

Jansen, S., Forbes, D., Duncan, V., Morgan Debra, G. and Malouf, R. (2011). Melatonin for the treatment of dementia. Cochrane Database of Systematic Reviews, 1, CD003802.

Laver, K., Dyer, S., Whitehead, C., Clemson, L. and Crotty, M. (2016). Interventions to delay functional 
decline in people with dementia: a systematic review of systematic reviews. BMF Open, 6, e010767.

Lyketsos, C. G., Steinberg, M., Tschanz, J. T., Norton, M. C., Steffens, D. C. and Breitner, J. C. (2000). Mental and behavioral disturbances in dementia: findings from the cache county study on memory in aging. American Fournal of Psychiatry, 157, 708-714.

Ma, H. et al. (2014). The efficacy and safety of atypical antipsychotics for the treatment of dementia: a meta-analysis of randomized placebo-controlled trials. Fournal of Alzheimer's Disease, 42, 915-937.

Moher, D., Altman, D. G., Liberati, A. and Tetzlaff, J. (2011). PRISMA statement. Epidemiology, 22, 128.

Moniz Cook, E. D., Swift, K., James, I., Malouf, R., De Vugt, M. and Verhey, F. (2012). Functional analysis-based interventions for challenging behaviour in dementia. Cochrane Database of Systematic Reviews, 2, CD006929.

Moore, M., Zhu, C. and Clipp, E. (2001). Informal costs of dementia care: estimates from the national longitudinal caregiver study. Fournal of Gerontology Series B: Psychological Sciences and Social Sciences, 56, S219-S228.

National Institute for Health and Clinical Excellence-Social Care Institute for Excellence (2007). Dementia. A NICE-SCIE Guideline on Supporting People with Dementia and Their Carers in Health and Social Care. London, UK: National Clinical Practice Guideline London.

Nelson, J. and Devanand, D. P. (2011). A systematic review and meta-analysis of placebo-controlled antidepressant studies in people with depression and dementia. Fournal of the American Geriatrics Society, 59, 577-585.

Orgeta, V., Qazi, A., Spector, A. E. and Orrell, $M$. (2014). Psychological treatments for depression and anxiety in dementia and mild cognitive impairment. Cochrane Database of Systematic Reviews, 1, CD009125.

Pieper, M. J. C. et al. (2013). Interventions targeting pain or behaviour in dementia: a systematic review. Ageing Research Reviews, 12, 1042-1055.

Savva, G. M. et al. (2009). Prevalence, correlates and course of behavioural and psychological symptoms of dementia in the population. British fournal of Psychiatry, 194, 212-219.
Schneider, L. S., Dagerman, K. S. and Insel, P. (2005). Risk of death with atypical antipsychotic drug treatment for dementia: meta-analysis of randomized placebo-controlled trials. $\mathcal{F A M A}, 294,1934-1943$.

Seitz, D. P., Adunuri, N., Gill Sudeep, S., Gruneir, A., Herrmann, N. and Rochon, P. (2011). Antidepressants for agitation and psychosis in dementia. Cochrane Database of Systematic Reviews, 2, CD008191.

Seitz, D. P. et al. (2013). Pharmacological treatments for neuropsychiatric symptoms of dementia in long-term care: a systematic review. International Psychogeriatrics, 25, 185-203.

Shea, B. J. et al. (2007). Development of AMSTAR: a measurement tool to assess the methodological quality of systematic reviews. BMC Medical Research Methodology, 7, 10.

Steele, C., Rovner, B., Chase, G. A. and Folstein, M. (1990). Psychiatric symptoms and nursing home placement of patients with Alzheimer's disease. American Fournal of Psychiatry, 147, 1049-1051.

Tan, C. C. et al. (2014). Efficacy and safety of donepezil, galantamine, rivastigmine, and memantine for the treatment of Alzheimer's disease: a systematic review and meta-analysis (Provisional abstract). Fournal of Alzheimer's Disease, 41, 615-631.

Ueda, T., Suzukamo, Y., Sato, M. and Izumi, S. (2013). Effects of music therapy on behavioral and psychological symptoms of dementia: a systematic review and meta-analysis. Ageing Research Reviews, 12, 628-641.

Van't Leven, N., Prick, A. E., Groenewoud, J. G., Roelofs, P. D., Lange, J. and Pot, A. M. (2013). Dyadic interventions for community-dwelling people with dementia and their family caregivers: a systematic review (Provisional abstract). International Psychogeriatrics, 25, 1581-1603.

Woods, B., Aguirre, E., Spector, A. E. and Orrell, $M$. (2012). Cognitive stimulation to improve cognitive functioning in people with dementia. Cochrane Database of Systematic Reviews, 2, CD005562.

Woods, B., Spector, A., Jones, C., Orrell, M. and Davies, S. (2005). Reminiscence therapy for dementia. Cochrane Database of Systematic Reviews, 2, CD001120. 